\title{
Self-Motion Perception Induced by Cutaneous Sensation Caused by Constant Wind
}

\author{
Kayoko Murata $^{1^{*}}$, Takeharu Seno ${ }^{2,3,4^{*}}$, Yoko Ozawa ${ }^{1}$, Shigeru Ichihara ${ }^{1^{*}}$ \\ ${ }^{1}$ Department of Human Sciences, Tokyo Metropolitan University, Tokyo, Japan \\ ${ }^{2}$ Faculty of Design, Kyushu University, Fukuoka, Japan \\ ${ }^{3}$ Institute for Advanced Study, Kyushu University, Fukuoka, Japan \\ ${ }^{4}$ Research Center for Applied Perceptual Science, Kyushu University, Fukuoka, Japan \\ Email: ${ }^{*}$ murata.kayoko0@gmail.com
}

Received 25 August 2014; revised 21 September 2014; accepted 18 October 2014

Copyright (C) 2014 by authors and Scientific Research Publishing Inc.

This work is licensed under the Creative Commons Attribution International License (CC BY).

http://creativecommons.org/licenses/by/4.0/

c) (i) Open Access

\begin{abstract}
We first in the history of vection research, challenged to induce cutaneous vection by providing the participants body with wind. Participants wore an eye mask to block out all outside visual information, and white noise was presented through a pair of earphones to block out all outside auditory information. We also provided body sway by using a horse-riding machine. The constant wind was provided to the participants from the front, side and behind of them. The results clearly showed that the cutaneous vection by wind was obtained in almost all participants. Even by only wind to the body could induce vection.
\end{abstract}

\section{Keywords}

Self-Motion, Wind, Cutaneous Sensation, Vestibular Motion, Perception

\section{Introduction}

Multiple sensory modalities contribute to the perception of self-motion (Gibson, 1966) and those inputs of multiple modalities are thought to be generally integrated in harmony (Rieser et al., 1995). These modalities include the visual, auditory, vestibular, somatosensory, and proprioceptive systems (Lishman \& Lee, 1973; Lee \& Aronson, 1974; Brandt et al., 1975; Johansson, 1977; Lestienne et al., 1977; Benson, 1990; Siegler et al., 2000; Sakamoto et al., 2004; Väljamäe, 2009; Sakurai et al., 2010; Seno et al., 2011). Even with only one input from

${ }^{*}$ Corresponding authors. 
one modality, we can create the perception of self-motion. The best example of this is visually induced self-motion perception, known as vection (Fischer \& Kornmüller, 1930). More recently, auditory vection has been described where perception of self-motion can be driven solely by an auditory input (see review, Väljämae, 2009). These results imply that self-motion perception can be induced by an input from just one modality.

In many other studies, the effects of combinations of some those inputs on the perception of self-motion have been investigated. For example, a number of studies have indicated that the visual and vestibular systems are associated with inducing self-motion (Dichgans et al. 1974; Berthoz \& Droulez 1982; Andersen 1986; Howard 1986). A recent study has verified that perceived self-motion can be induced when head movement is synchronized with jitter (Ash et al., 2013). Vection can be facilitated or inhibited by some inputs from multiple modalities (e.g., Seno, Ito, \& Sunaga, 2011; Seno et al., 2012; Seno et al., 2011). For example, vection can be enhanced by a consistent wind to the faces of the observers (Seno et al., 2011) and also vection can be facilitated by consistent sounds (Seno et al., 2012). However, we should note here that there has been no previous study to examine whether cutaneous sensation alone can induce the perception of self-motion or not.

Theoretically, wind or changes of air pressure perceived on the skin can also be a source of perceived selfmotion perception. For example, when we are moved passively on a vehicle, or actively by walking or running, we perceive the wind blowing on the body. It has been reported anecdotally that cutaneous sensation may work as a more important sensory modality for totally blind or deaf-blind people (e.g., Mutaguchi, 2012).

We hypothesized that wind (cutaneous sensation) accompanied by the real self-motion can induce illusory self-motion perception or when wind alone is directed at the participants. The purpose of this study was to examine whether the wind, without any visual or auditory stimulation, can induce the self-motion perception (cutaneous vection).

In a pilot study, we found that cutaneous vection was relatively weaker (as is auditory vection) than that driven by vision (hereafter we use the term vection as visually induced self-motion perception). We added a facilitator of cutaneous vection, i.e., body fluctuation using a horse-riding machine, as it had been shown that fluctuation of the body can enhance vection (e.g. Riecke et al., 2005; Feuereissen, 2008). Some previous studies also reported that body posture can alter vection strength (e.g., Seno et al., 2013; Kano, 1991; Nakamura \& Shimojo, 1998; Young \& Shelhamer, 1990; Mueller et al., 1994; Allison et al., 2012). For example, some studies reported that vection strength differed with body orientation and body posture (e.g., Kano, 1991; Nakamura \& Shimojo, 1998). Young \& Shelhamer, (1990), Mueller et al., (1994) and Allison et al. (2012) reported that vection in a microgravity condition became unstable and sometimes could be induced in the opposite direction to the normal vection or it could be facilitated. In another study Feuereissen (2008) reported that the unstable body condition on the hammock chair can enhance auditory vection. He (Feuereissen, 2008) and Riecke et al. (2005) also reported that the auditory vection can be facilitated by subsonic vibrations to the participants. These results strongly indicate that body posture could be an important facilitator or inhibitor of vection. Therefore, we hypothesized that the unstable posture induced by the horse-riding machine, might facilitate the weak cutaneous vection in this study. The body fluctuation by a horse-riding machine provided the participants with unidirectional (back and forth) body movement, therefore it could not bias any direction of self-motion perception.

\section{Methodology}

We examined whether self-motion perception could be obtained when the wind blew on the body without confounding visual or auditory stimuli. We also examined whether the body fluctuation could facilitate any cutaneous vection.

\subsection{Ethics Statement}

Our experiments were pre-approved by the Ethics Committee of Tokyo Metropolitan University, and written informed consent was obtained from each participant prior to testing.

\subsection{Participants}

Thirteen graduate and undergraduate students and lecturers, (five females and eight males aged between 21 and 43 years) participated in the experiment. All participants had normal visual acuity (including corrected eyesight), normal audition and no history of vestibular system diseases. Further, all of the participants were naive as to the purpose of the experiment. 


\subsection{Stimulus and Apparatus}

We used a horse-riding machine moving back and forth reciprocally (Joba, EU6442, Panasonic Corporation, Japan) to provide the sway. We also used a fan (FIR401, Pieria Corporation) to apply wind to each participant's body and face. The wind had a constant strength (wind speed, $5.5 \mathrm{~m} / \mathrm{s}$ ) and blew from either the front of, or from the right side of, or from behind (front, side, or back, respectively) the participant. Participants wore an eye mask to block out all outside visual information, and white noise (64 dB SPL) was presented through a pair of earphones to block out all outside auditory information (see Figure 1). Thus, there were totally no visual or auditory inputs that might contribute movement cues to the participants ${ }^{1}$.

\subsection{Procedure}

We first confirmed that no participant experienced motion sickness in the training trial. There were three wind with sway conditions and three wind only conditions (without body sway) as the experimental conditions. The fan blew with the movement of the horse-riding machine in the wind with sway conditions, while the fan blew without the movement of the horse-riding machine in the wind only conditions. The wind directions in these conditions were from the front, from the right side or from the back of the participants. The fan and the horse-riding machine began to move simultaneously in the wind with sway conditions. In addition to these, there was a control condition in which only the body swayed without the fan blowing.

The participants were asked whether they perceived self-motion in the one control and six experimental conditions. All of the conditions were presented once in a random order for each participant.

The participants were instructed to rate the subjective strength of the self-motion with estimated values that ranged from 0 (no self-motion) to 5 (very strong self-motion). They reported their estimation verbally. The duration of wind and body sway stimuli was fixed at $60 \mathrm{~s}$. At the end of a trial, in the case that the participants perceived the cutaneous vection, they answered the questionnaire about the perceived direction of the cutaneous vection and also they reported their impressions of it freely for each trial.

\section{Results}

All thirteen participants perceived cutaneous vection in the front wind with sway condition. Eleven participants perceived cutaneous vection in the right side wind with sway condition. Twelve participants perceived cutaneous vection in the back wind with sway condition. Three participants perceived the cutaneous vection in the front wind only condition. Three participants perceived the cutaneous vection in the right side wind only condition. Four

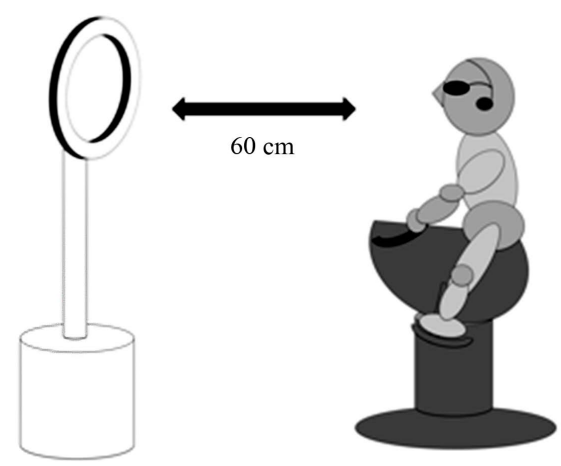

Figure 1. The layout of the fan to blow wind and the exercise machine to sway the participant's body. We used a fan (FIR401, PIERIA) to apply wind to each participant's face and body (from front, side and back). The fan distance from participants was $60 \mathrm{~cm}$. The wind had a constant strength (wind speed was $5.5 \mathrm{~m} / \mathrm{s}$ ) and blew from the front, the right side, or behind (front, side, back) the participant. Participants wore an eye mask to prevent outside visual information, and white noise was presented through a pair of earphones to cut out all external auditory information. The machine's seat moved back and forth to cause the body sway and stimulate the vestibular senses. The moving distance (one way) was $7 \mathrm{~cm}$. Its speed was $7 \mathrm{~cm} / \mathrm{s}$.

${ }^{1}$ White noise is not absence of sound. The key point here is that there are no other moving sensory inputs. 
participants perceived the cutaneous vection in the back wind only conditions. Eight participants perceived some illusory motion perception in the sway only (control) condition. The perceived self-motion was in the opposite direction than the wind. In the sway only condition there was no directionality in the self-motion illusion.

Figure 2 shows the mean estimation values of the subjective strength of self-motion for all six conditions. A two-way analysis of variance (ANOVA) was conducted. The existence or non-existence of the body sway and the three directions of wind were the two factors of this ANOVA $^{2}$. The results revealed significant main effects of the existence of the sway $(\mathrm{F}(1,12)=101.21, p=0.000)$ and a tendency of a significant main effect of the directions of wind $(F(2,24)=2.62, p=0.094)$. Further, the interaction between the two factors was also significant $(F(2,24)=$ $3.63, p=0.042$ ). The simple main effects of the existence of the sway were significant in all wind directions (front: $\mathrm{F}(1,36)=70.45, p=0.000$; right side: $\mathrm{F}(1,36)=25.36, p=0.000$; back: $\mathrm{F}(1,36)=30.42, p=0.000)$ and the simple main effect of wind direction was significant only in the with sway condition $(\mathrm{F}(2,48)=6.09, p=0.004)$.

Figure 3 shows the number of the reports of directions of the cutaneous vection for each condition. The results of Fisher's exact test $(p=0.000)$ showed that $\mathrm{p}$ was less than 0.01 . In the sway only (control) condition, no one reported any direction of perceived self-motion. Participants perceived cutaneous vection in the opposite directions to the physical wind directions.

\section{Discussion}

Although self-motion perception induced by visual or auditory stimuli has been extensively studied, cutaneous vection has not been investigated. Only Seno et al. (2011) showed that wind corresponding with visual stimuli facilitated vection. This is the first study on whether the cutaneous sensation from the wind could induce selfmotion perception or not. We obtained clear results that cutaneous vectioncan occur. We also showed that the strength of the cutaneous vection was different depending on the wind directions. We took precautions to mask any experimenter bias and do not consider that these results originated from the expectations of the participants. However thirteen participants might be a small number and it should be presented as a limitation of the research in the discussion section.

Cutaneous vection was induced in every direction and the reports from the questionnaires showed that the direction of the cutaneous vection was usually opposite to that of the blowing wind. Further, these results were consistent with features of visually induced self-motion (the simple "vection") and also the auditory vection, reported in many previous studies (e.g., Lee \& Aronson, 1974; Johansson, 1977; Wong \& Frost, 1981; Kano, 1991; Lackner, 1977; Riecke et al., 2005; Väljämae, 2009).

In the sway-only condition, self-motion was reported, but the directions of such perceived self-motion was not determined. In the without sway and only with wind conditions, weaker but still substantial cutaneous vection was obtained. In the experiment, three participants perceived cutaneous vection in the front wind only condition,

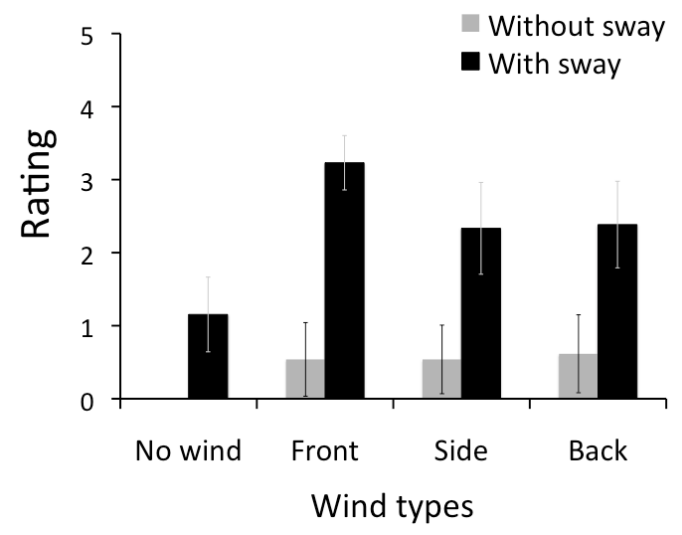

Figure 2. The effect on perceived self-motion of wind directions either with or without sway. Subjective estimation of perceived self-motion strength. The $\mathrm{x}$-axis denotes the condition (one control condition, three wind-only conditions, and three wind-withbody-sway conditions). Error bars indicate the standard error of mean.

\footnotetext{
${ }^{2}$ In addition to those six conditions, we also conducted a control condition, i.e., with only body sway without wind condition. We excluded this condition from this ANOVA because we focused on the with wind conditions only.
} 


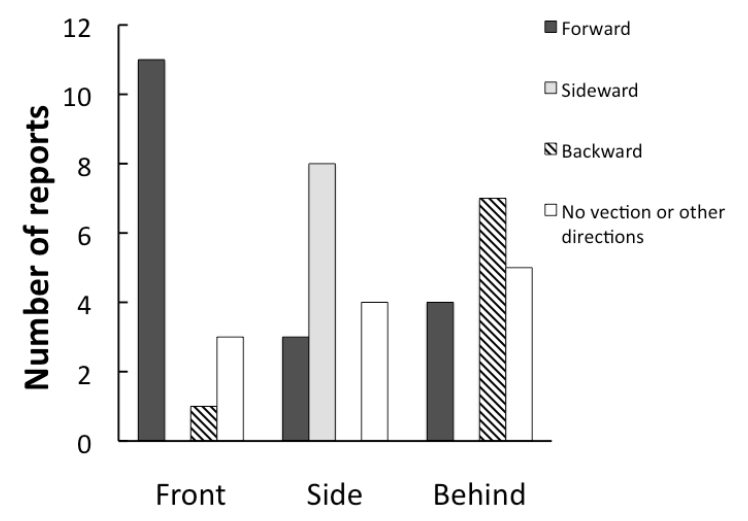

Figure 3. The direction of perceived self-motion from each wind directions from the questionnaire results. The $\mathrm{x}$-axis is the wind direction condition. The $\mathrm{y}$-axis is number of reports. Four types of bars indicate the direction of the illusory self-motion perception.

also three in the right side and four in the back wind only condition. Like auditory vection, cutaneous vection is weaker than the normal vection. Thus, the combination of body sway and the wind was necessary to induce stronger cutaneous vection. However as described in the introduction, the horse-riding machine did not bias any direction of self-motion. It provided the participant with unidirectional (back and forth) body fluctuations. We consider our methodology was suitable to enhance the effect of the wind. In future, it would be useful for trying other methods to enhance cutaneous vection.

After the experiment, the participants freely described what they perceived during the experiments. They reported a floating perception and a perception of movement in the opposite direction to that of the wind motion. Most participants reported a perception of floating forward and upward, like running on a field of grass. They reported a pleasant perception like being refreshed. The participants' pleasant perceptions in this study were also of merit. We hope that the cutaneous vection will be used in various environments of virtual reality in future. We believe that the various uses of this cutaneous vection could have many applications in future.

\section{Acknowledgements}

This work is supported by the Program to Disseminate Tenure Tracking System, MEXT, and also by Grant-inAid for Young Scientists (A), Japan to TS.

We would like to thank Professor Yoko Hirai (Tokyo Metropolitan University) for her having guided about statistical inference.

We would like to thank Professor Kazuo Koga and Tsutomu Kusano for their helpful advice to our study.

\section{References}

Allison, R. S., Zacher, J. E., Kirollos, R., Guterman, P. S., \& Palmisano, S. (2012). Perception of Smooth and Perturbed Vection in Short-Duration Microgravity. Experimental Brain Research, 223, 479-487.

http://dx.doi.org/10.1007/s00221-012-3275-5

Andersen, G. J. (1986). Perception of Self-Motion: Psychophysical and Computational Approaches. Psychological Bulletin, 99, 52-65. http://dx.doi.org/10.1037/0033-2909.99.1.52

Ash, A., Palmisano, S., Apthorp, D., \& Allisom, R. S. (2013). Vection in Depth during Treadmill Walking. Perception, 42, 562-576. http://dx.doi.org/10.1068/p7449

Benson, A. J. (1990). Sensory Functions and Limitations of the Vestibular System. In R. Warren \& A. H. Wertheim (Eds.), The Perception and Control of Self-Motion (pp. 145-170), Hillsdale, NJ: Lawrence Erlbaum Associates.

Berthoz, A., \& Droulez, J. (1982). Linear Self-Motion Perception. In A. H. Wertheim, W. A. Wagenaar \& H. W. Leibowitz (Eds.), Tutorials on Motion Perception (pp. 157-199), London: Plenum.

Brandt, T., Wist, E. R., \& Dichgans, J. (1975). Foreground and Background in Dynamic Spatial Orientation. Perception \& Psychophysics, 17, 497-503.

Dichgans, J., Bizzi, E., Morasso, P., \& Tagliasco, V. (1974). The Role of Vestibular and Neck Afferents During Eye-Head 
Coordination in the Monkey. Brain Research, 71, 225-232. http://dx.doi.org/10.1016/0006-8993(74)90964-0

Feuereissen, D. (2008). VR: Getting the Reality Part Straight-Does Jitter and Suspension of the Human Body Increase Auditory Circular Vection? Bachelor's Thesis, Department of Computer Science in Media.

Fischer, M. H., \& Kornmüller, A. E. (1930). Optokinetischausgelöste Bewegungswahrnehmung und optokinetischer Nystagmus. Journal fur Psychologie und Neurologie (Leipzig), 41, 273-308.

Gibson, J. J. (1966). The Senses Considered as Perceptual Systems. Boston, MA: Houghton Mifflin.

Howard, I. P. (1986). The Perception of Posture, Self Motion and the Visual Vertical. In K. R. Boff, L. Kaufman, \& J. P. Thomas (Eds.), Handbook of Perception and Human Perception (pp. 18-1-18-62). New York: Wiley \& Sons.

Johansson, G. (1977). Studies on Visual-Perception of Locomotion. Perception, 6, 365-376. http://dx.doi.org/10.1068/p060365

Kano, C. (1991). The Perception of Self-Motion Induced by Peripheral Visual Information in Sitting and Supine Postures. Ecological Psychology, 3, 241-253. http://dx.doi.org/10.1207/s15326969eco0303 3

Lackner, J. R. (1977). Induction of Illusory Self-Motion and Nystagmus by a Rotating Sound-Field. Aviation, Space and Environmental Medicine, 48, 129-131.

Lee, D. N., \& Aronson, E. (1974). Visual Proprioceptive Control of Standing in Human Infants. Perception \& Psychophysics, 15, 529-532.

Lestienne, F., Soechting, J., \& Berthoz, A. (1977). Postural Readjustments Induced by Linear Motion of Visual Scenes. Experimental Brain Research, 28, 363-384.

Lishman, J. R., and Lee, D. N. (1973). The Autonomy of Visual Kinaesthesis. Perception, 2, 287-294. http://dx.doi.org/10.1068/p020287

Mueller, C. H., Kornilova, L., Wiest, G., \& Steinhoff, N. (1994). Psychophysical Studies of Visuo-Vestibular Interaction in Microgravity. Acta Astronautica, 33, 9-13. http://dx.doi.org/10.1016/0094-5765(94)90102-3

Mutaguchi, T. (2012). A Study on the Development of Orientation and Mobility Instruction Program for the Blind Children. In T. Mutaguchi (Principal Investigator), 2008-2011 Ministry of Education, Science and Culture Grants-in-Aid for Scientific Research (C) Research Report.

Nakamura, S., \& Shimojo, S. (1998). Orientation of Selective Effects of Body Tilt on Visually Induced Perception of Self-Motion. Perceptual and Motor Skills, 87, 667-672. http://dx.doi.org/10.2466/pms.1998.87.2.667

Riecke, B. E., Schulte-Pelkum, J., Caniard, F., \& Bülthoff, H. H. (2005). Influence of Auditory Cues on the Visually-Induced Self-Motion Illusion (Circular Vection) in Virtual Reality. In Proceedings of 8th Annual Workshop Presence 2005 (pp. 49-57). New York: ACM Press.

Rieser, J. J., Pick, H. L., Ashmead, D. H., \& Garing, A. E. (1995). Calibration of Human Locomotion and Models of Perceptual-Motor Organization. Journal of Experimental Psychology: Human Perception and Performance, 21, 480-497. http://dx.doi.org/10.1037/0096-1523.21.3.480

Sakamoto, S., Osada, Y., Suzuki, Y., \& Gyoba, J. (2004).The Effects of Linearly Moving Sound Images on Self-Motion Perception. Acoustical Science and Technology, 25, 100-102. http://dx.doi.org/10.1250/ast.25.100

Sakurai, K., Kubodera, T., \& Grove, P. (2010). Multi-Modally Perceived Direction of Self-Motion from Orthogonally Directed Visual and Vestibular Stimulation. Journal of Vision, 10, 866. http://dx.doi.org/10.1167/10.7.866

Seno, T., Funatsu, F., \& Palmisano, S. (2013). Virtual Swimming-Breaststroke Body Movements Facilitate Vection. Multisensory Research, 6, 267-275.

Seno, T., Hasuo, E., Ito, H., \& Nakajima, Y. (2012). Perceptually Plausible Sounds Facilitate Visually Induced Self-Motion Perception (Vection). Perception, 41, 577-593. http://dx.doi.org/10.1068/p7184

Seno, T., Ito, H., \& Sunaga, S. (2011). Inconsistent Locomotion Inhibits Vection. Perception, 40, 747-750. http://dx.doi.org/10.1068/p7018

Seno, T., Ogawa, M., Ito, H., \& Sunaga, S. (2011). Consistent Air Flow to the Face Facilitates Vection. Perception, 40, 1237-1240. http://dx.doi.org/10.1068/p7055

Siegler, I., Viaud-Delmon, I., Israël, I., \& Berthoz, A. (2000). Self-Motion Perception during a Sequence of Whole-Body Rotations in Darkness. Experimental Brain Research, 134, 66-73. http://dx.doi.org/10.1007/s002210000415

Väljamäe, A. (2009). Auditorily-Induced Illusory Self-Motion: A Review. Brain Research Review, 61, $240-255$. http://dx.doi.org/10.1016/j.brainresrev.2009.07.001

Wong, S. C. P., \& Frost, B. J. (1981). The Effect of Visual-Vestibular Conflict on the Latency of Steady-State Visually Induced Subjective Rotation. Perception \& Psychophysics, 30, 228-236.

Young, L. R., \& Shelhamer, M. (1990). Microgravity Enhances the Relative Contribution of Visually-Induced Motion Sensation. Aviation, Space and Environmental Medicine, 61, 525-530. 
Scientific Research Publishing (SCIRP) is one of the largest Open Access journal publishers. It is currently publishing more than 200 open access, online, peer-reviewed journals covering a wide range of academic disciplines. SCIRP serves the worldwide academic communities and contributes to the progress and application of science with its publication.

Other selected journals from SCIRP are listed as below. Submit your manuscript to us via either submit@scirp.org or Online Submission Portal.
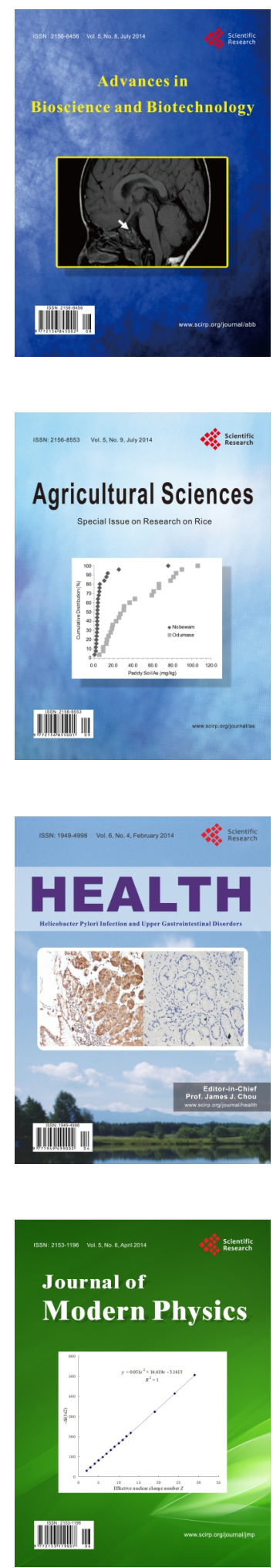
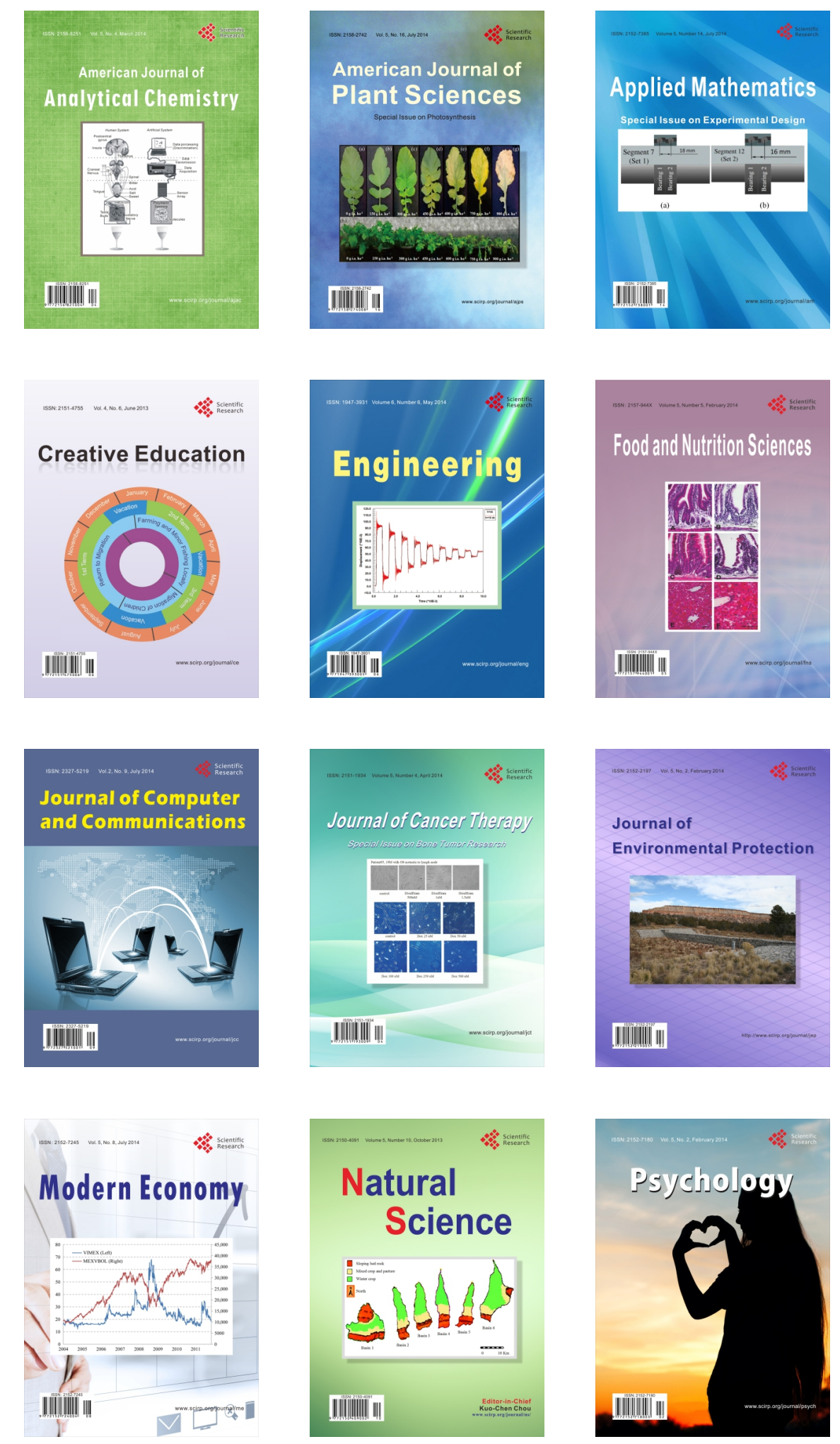